\title{
Association between physician explanatory behaviors and substandard care in adjudicated cases in Japan
}

\author{
Akihito Hagihara' \\ Tomoko Hamasaki ${ }^{2}$ \\ Takeru Abe' \\ 'Department of Health Services \\ Management and Policy, Kyushu \\ University Graduate School \\ of Medicine, Higashi-ku, Fukuoka, \\ Japan; ${ }^{2}$ Department of Nutrition \\ Faculty of Home Economics, Kyushu \\ Women's University, Yahatanishi, \\ Kitakyushu, Fukuoka, Japan
}

This article was published in the following Dove Press journal:

International Journal of General Medicine

I I April 201 I

Number of times this article has been viewed

Background: When a physician provides an insufficient explanation to a patient, such as regarding diagnosis, treatment, drug use, or prognosis, the physician is deemed to have delivered substandard care. It is likely that the standards applied to physicians' explanations have changed as a result of the increased importance of patients' rights of self-determination. However, little or no research on decisions in medical malpractice cases has been conducted with respect to this issue.

Methods: Based on decisions made in 366 medical malpractice cases between 1979 and 2008 focused primarily on the physician's duty to explain relevant issues to patients, we examined the association between physicians' explanatory behaviors and court decisions with respect to breaches of duty.

Results: We found that physicians' explanatory behaviors, including relevant and specific explanations provided before treatment or surgery, were important for fulfilling a physician's duty to explain. The data also revealed that six of the 16 types of explanatory behaviors had improved during the past three decades. However, these improvements did not contribute to the fulfillment of the physician's duty to explain.

Conclusion: We found that there was an association between physicians' explanatory behaviors and judicial decisions concerning substandard care, and courts were increasingly likely to consider inadequate explanatory behaviors to be a breach of the duty of care.

Keywords: physician, explanation, patient rights, self-determination

\section{Introduction}

A patient's dissatisfaction with a physician's explanation, such as in regard to treatment, drug use, or prognosis, tends to manifest when the health outcome falls short of expectations, even in the absence of problems with a physician's medical judgment or technical performance. According to a survey of medical malpractice litigation in recent years in Japan, the number of cases focusing on physicians' explanations to patients has increased. ${ }^{1}$ According to an analysis of medical malpractice claims in the US ending in payments of a million dollars or more, the second largest group of claims were related to the "failure of physicians to inform patients of possible outcomes". ${ }^{2}$ It has been reported that physicians' explanations and the level of patients' understanding are related to patient satisfaction, treatment adherence, and treatment outcome. ${ }^{3-5}$ Furthermore, it has been recently shown that inappropriate explanations by physicians regarding issues, such as treatment, drug use, and prognosis, can lead to medical disputes..$^{6-11}$ Thus, the explanatory behavior of physicians plays an important role in improving patient satisfaction, preventing medical disputes, and increasing
Correspondence: Akihito Hagihara Department of Health Services Management and Policy, Kyushu University Graduate School of Medicine, 3-I-I Maidashi, Higashi-ku, Fukuoka, 812-8582, Japan

Tel +81926426950

$\mathrm{Fax}+81926426961$

Email hagihara@hsmp.med.kyushu-u.ac.jp 
treatment effectiveness. In view of the importance of these explanatory behaviors in medical settings, researchers have conducted various types of studies and identified elements in physicians' explanatory behaviors that are closely related to medical disputes. These elements have included engaging in less social talk, showing less sympathy toward or interest in patients, devoting less time to patient appointments, and providing an environment rendering it difficult to ask questions of physicians. ${ }^{12,13}$

A patient has the right to determine what is going to be done with his or her body. Securing the patient's right of self-determination requires that the doctrine of informed consent be guaranteed. ${ }^{14}$ In other words, the patient's right to receive an adequate explanation about his or her treatment from the doctor needs to be fully guaranteed. Thus, we can safely assert that the physician's duty to explain to the patient is closely related to the patient's right of self-determination. ${ }^{15}$ Legally, the physician's duty to provide relevant explanations to the patient constitutes part of the medical contract between physician and patient. When the physician provides an inadequate explanation to the patient, the physician is deemed to have delivered substandard care, even if no fault can be found with respect to his/her medical judgment or technical skills, ${ }^{16}$ because an inadequate explanation by a physician constitutes a failure to fulfill a portion of the physician's duties contained in the medical contract.

Because decisions in litigated medical malpractice cases provide useful information about patient-physician interactions, we analyzed litigated medical malpractice cases in Japan ${ }^{17-19}$ to examine the association between physicians' explanatory behaviors and their legal liability, and identified a connection between physicians' specific manner of listening or talking to patients and their families and court decisions with respect to negligent care. ${ }^{20}$ The patient's right of selfdetermination in the medical setting has become increasingly important during recent years. ${ }^{15,21-23}$ Thus, the standards for physicians' explanatory behaviors may have changed because the manner and content of these explanatory behaviors are related to physicians' duty to explain and to patients' rights of self-determination. Because little or no data exist on this topic, we examined the following questions. What explanatory behaviors are necessary for fulfilling the physician's legal duty to explain relevant matters to the patient and thereby avoid the delivery of substandard care? Have physicians' explanatory behaviors to patients improved during the past three decades, given the increased importance of patients' rights of self-determination? Has any improvement in physicians' explanatory behaviors during the past three decades contributed to fulfillment of physicians' legal duty to explain relevant issues to patients and to the subsequent avoidance of delivering substandard care? We believed that these analyses would yield interesting data with practical implications.

\section{Methods \\ Data source}

We analyzed the decisions in litigated medical malpractice cases reported in the Hanrei Jiho and Hanrei Taimuzu, major case-record reports of adjudicated litigated cases in Japan. We focused on those cases occurring between 1979 and 2008 in which the pivotal issue was a physician's duty to explain, and identified 366 cases.

\section{Data coding}

Under the direction of one of the authors (TH), three students at Kyushu Dental College carefully read the decisions. Before reading the decisions, the students attended sessions to learn about the structure of a decision, variables related to physician explanatory behaviors, legal decisions, and patient and physician factors. One of the authors (TH) read all the decisions, and each student carefully read about one-third of the decisions included in the analysis. After reading all the decisions, the content of each decision was summarized according to the study variables, and a database comprising the content of each decision $(n=366)$ was constructed. To verify the validity of the data coding with respect to the nine variables related to physicians' explanatory behaviors, kappa measures of agreement were calculated. With respect to variables related to physicians' explanatory behaviors, shown in Table 3, kappa measures of interrater agreement between one of the authors (TH) and the three students were calculated. We obtained values of $0.77,1.0$, and 1.0 for the first variable (purpose of explanation); 0.91, 0.96, and 0.87 for the second variable (provision of an explanation by physician); 0.94 , 0.94 , and 0.87 for the third variable (timing of physician's explanation); $0.94,1.00$, and 0.74 for the fourth variable (recipient of physician's explanation); 0.80, 1.00, and 0.76 for the fifth variable (manner of physician's explanation to the patient); $0.91,1.00$, and 0.76 for the sixth variable (manner of physician's explanation to the family); $0.61,1.00$, and 1.00 for the seventh variable (level of physician's explanation to the patient); $0.61,1.00$, and 1.00 for the eighth variable (level of physician's explanation to family); and 0.82, 0.81, and 0.83 for the ninth variable (place in which physician's explanation occurred). In summary, these findings indicated good interrater agreement. When the coding among the four 
raters differed, the cases were discussed on the basis of the coding criteria, and a consensus was reached.

\section{Study variables}

Patient and physician variables are listed in Table 2. Issues involved in medical malpractice litigation are also listed in this table. Of the patient characteristics, "type of treatment" had two subcategories, ie, "elective or not urgently necessary" and "other". Indeed, a difference between cosmetic surgery and other medical treatments exists with respect to the criteria applied to physicians' explanations to patients. The physicians' duty to provide an explanation to the patient is severely judged in the field of cosmetic surgery, where treatment is not urgently needed but is elective. ${ }^{24}$ Thus, type of treatment was divided into these two categories. "Severity of injury" was subdivided into categories of "death" and "other". The latter included temporary and resolved injuries as well as permanent or continuing injuries.

It has been reported that poor patient-physician communication is predictive of medical claims against internists but not against surgeons. ${ }^{9}$ Based on this finding, the "department in which patients were treated" was divided into two subcategories, "surgical" and "other". The type of medical facility was classified as a clinic or a hospital, based on the Japanese law specifying that "a medical institution having hospitalization facilities with more than 20 beds" is defined as a hospital, and "a medical institution having hospitalization facilities with 19 beds or fewer" is defined as a clinic (Medical Law, Article 5, Law No. 205, 1948). When the treatment in question has not been established as standard at the time of delivery, the level of the physician's explanation of the treatment is not required to be as sophisticated as it is in cases in which the treatment has been deemed to be standard. "Medical standard" is a court judgment with respect to whether a treatment has been established as medically standard; judgments of standard care and nonstandard care were included. Additionally, a physician's apology is often regarded as an indicator that the physician has admitted an error with respect to medical judgment or technical matters. ${ }^{25}$ "Physician's apology" was divided into "presence" and "absence". It is probable that a surgeon will care for a hypertensive or diabetic patient. "Physician's status as a specialist" was a court judgment with respect to whether care was provided by a specialist; "yes" and "no" judgments were possible.

Table 3 lists variables related to physicians' explanatory behavior. "Purpose of explanation" included "explanation to obtain patient's consent" and "other". As a general rule, physician explanations are to obtain the patient's consent, to provide guidance for medical treatment, and to provide post-treatment explanations. Of these, explanation to obtain patient consent is related to the patient's right of selfdetermination, indicating that explanation for this purpose differs from those for other purposes. "Timing of physician's explanation" was divided into two categories according to when the explanation was given, ie, "prior to treatment or surgery" or "after treatment or surgery".

In Japanese medical settings, the family tends to play an important role when physicians deliver explanations. Thus, "recipient of physicians' explanation" included two categories, ie, "patient", "family and patient", and "family only". "Manner of physician's explanation to the patient" and "manner of physician's explanation to the family" were each subdivided into two categories, ie, "oral only" and "oral and other methods". Other methods included documents and pamphlets. "Level of the physician's explanation to the patient" and "level of the physician's explanation to the family" were classified as "relevant and specific to treatment" or "not sufficiently relevant or specific to treatment", according to raters' judgments about the relevance and specificity of the explanation.

"Place in which the physician's explanation was provided" was classified as "inpatient ward" or "outpatient clinic". It is generally recognized that a doctor needs to explain fully what is happening to the patient when treatment is closely related to life or health. Therefore, "content of physicians' explanations" was categorized as "related to surgery or treatment" or "other". Consent by the patient or family (ie, "patient consent to treatment" or "family consent to treatment") included two categories, ie, "yes" and "no". With respect to written consent by the patient or family, cases in which a clear consent document was present were classified as "yes". Finally, "physicians explanation prior to the day of surgery or treatment" referred to the time at which the explanation was completed; this variable was categorized as "no" if the explanation was completed on the day of the surgery or treatment and as "yes" if it was completed before the day of the surgery or treatment.

\section{Statistical analysis}

The year of the court decision was used as a surrogate variable for the patient's legal right of self-determination. Because these years ranged between 1979 and 2008, decisions were categorized into three periods, ie, 1979-1989, 1990-1999, and 2000-2008. Because the timing of the court decision approached the present, the patient's right of 
self-determination in medical settings became increasingly important. ${ }^{15,21-23}$ To evaluate the association between patient characteristics, physician characteristics, or physicians' explanatory behavior and the period of the decision, the Student's $t$-test for continuous variables or the $\chi^{2}$ test for categorical variables was used. The statistical software package SPSSx version 11 (SPSS Inc, Chicago, IL) was used for the analysis.

\section{Results}

Table 1 shows the number of cases by type of physician liability and year of the court decision. The ratio of cases in which physicians were held legally liable increased from $34.4 \%$ during $1979-1989$ to $78.1 \%$ during 2000-2008. Additionally, the ratio of cases in which a physician's breach of his/her duty to explain to the patient was acknowledged increased from $18.9 \%$ during 1979-1989 to 54.8\% during 2000-2008. The ratio of cases in which the physician was found to be at fault with respect to medical judgment or technical procedures increased from 30.3\% during 1979-1989 to $48.6 \%$ during $2000-2008$.

Table 2 shows changes in the characteristics of plaintiffs (ie, patients), physicians, and medical litigation over time. The mean age of patients and the ratio of severe injuries (ie, ending in death) significantly increased as a function of time ( $P=0.000$ and 0.001 , respectively). The standard of care, the presence of a physician's apology, and the prevalence of specialists significantly also increased over time $(P=0.000$, 0.009 , and 0.002 , respectively). The prevalence of cases using medical expert witnesses, involving families only acting as plaintiffs, and including four or more issues, significantly increased as a function of time $(P=0.000,0.000$, and 0.023 , respectively). In addition, the ratio of damages awarded to damages sought and the amount of damages actually awarded significantly increased during the study period $(P=0.000)$.
Table 3 shows how physicians' explanatory behaviors in the litigated cases have changed during the period between 1979 and 2008. Of 16 explanatory behaviors, six have changed. Specifically, the prevalence of explanations to obtain consent from anyone $(P=0.000)$, from patients and family members $(P=0.000)$, and in written as well as verbal form from the patient $(P=0.043)$ or the family $(P=0.035)$ increased between 1979 and 2008. Conversely, the ratio of cases without physician explanation $(P=0.000)$ and with physician oral explanation only $(P=0.004)$ decreased between 1979 and 2008 .

Table 4 shows physicians' explanatory behaviors related to an acknowledged breach of duty to explain according to the period of the court decision. Of the 16 explanatory behaviors, the level of the physicians' explanation to the patient or to the family was related to the decision concerning the breach of a physician's duty to explain during all three periods. As the decision period approached the present, the prevalence of relevant and specific explanations in cases involving duty to explain that were decided in favor of the physician increased (level of physician's explanation to the patient: $42.3 \%, 57.7 \%$, and $86.8 \%$, respectively, and level of physician's explanation to the family: $45.5 \%$, $66.7 \%$, and $89.3 \%$, respectively). The timing of a physician's explanation and providing the explanation prior to the day of surgery or treatment were also related to the decision concerning the committing of a breach of duty to explain. After 1990-1999, compared with the prevalence of physician explanations occurring prior to treatment or surgery and prior to the day of surgery or treatment from 1979 to 1989 , the prevalence of the physician's explanatory behaviors increased among cases decided in favor of the physician (timing of physician's explanation: $88.6 \%$, and $91.7 \%$, respectively, and physician's explanation prior to the day of surgery or treatment: $96.3 \%$ and $90.2 \%$, respectively).

Table I Number of cases by type of physician liability and decision year

\begin{tabular}{|c|c|c|c|}
\hline & \multicolumn{3}{|c|}{ Period of decisions } \\
\hline & $\begin{array}{l}1979-1989 \\
(n=122)\end{array}$ & $\begin{array}{l}1990-1999 \\
(n=98)\end{array}$ & $\begin{array}{l}2000-2008 \\
(n=146)\end{array}$ \\
\hline I. Court decided in favor of physician's legal liability (\%) & $42(34.4 \%)$ & $61(62.2 \%)$ & $114(78.1 \%)$ \\
\hline $\begin{array}{l}\text { 2. Court decision acknowledged physician's fault with respect } \\
\text { to medical judgment or technical procedures (\%) }\end{array}$ & $31(23.0 \%)$ & 35 (25.9\%) & $69(51.1 \%)$ \\
\hline $\begin{array}{l}\text { 3. Court decision acknowledged breach with respect to } \\
\text { physician's duty to explain (\%) }\end{array}$ & $23(15.9 \%)$ & $4 \mathrm{I}(28.3 \%)$ & $8 \mathrm{l}(55.9 \%)$ \\
\hline $\begin{array}{l}\text { 4. Court decision acknowledged physician's fault with respect } \\
\text { to both medical judgment or technical procedures and breach } \\
\text { of duty to explain (\%) }\end{array}$ & $12(18.8 \%)$ & $15(23.4 \%)$ & $37(57.8 \%)$ \\
\hline
\end{tabular}


Table 2 Comparison of patient and physician characteristics by period of decision

\begin{tabular}{|c|c|c|c|c|}
\hline \multirow[t]{3}{*}{ Items } & \multicolumn{3}{|l|}{ Period } & \multirow[t]{3}{*}{$P^{d}$} \\
\hline & $1979-1989$ & $1990-1999$ & $2000-2008$ & \\
\hline & $(n=122)^{a}$ & $(n=98)^{b}$ & $(n=146)^{c}$ & \\
\hline \multicolumn{5}{|l|}{ Patients } \\
\hline I. Patient age (years) & $22.07 \pm 22.30$ & $40.17 \pm 21.73$ & $47.43 \pm 21.70$ & $0.000^{*}$ \\
\hline 2. Male/female & $65(54.6) / 54(45.4)$ & $51(53.1) / 45(46.9)$ & $69(47.9) / 75(52.1)$ & 0.520 \\
\hline $\begin{array}{l}\text { 3. Type of treatment: elective or } \\
\text { not urgently necessary/other }\end{array}$ & $7(5.7) / 115(94.3)$ & $9(9.2) / 89(90.8)$ & $17(11.6) / 129(88.4)$ & 0.228 \\
\hline 4. Severity of injury: death/other ${ }^{f}$ & $37(30.3) / 85(69.7)$ & $46(46.9) / 52(53.1)$ & $77(52.7) / 69(47.3)$ & $0.00 I^{*}$ \\
\hline \multicolumn{5}{|l|}{ Physicians } \\
\hline $\begin{array}{l}\text { I. Department in which patients } \\
\text { were treated: surgical/other }\end{array}$ & $43(35.2) / 79(64.8)$ & $46(46.9) / 52(53.1)$ & $60(4 \mid .1) / 86(58.9)$ & 0.213 \\
\hline $\begin{array}{l}\text { 2. Type of medical facility, } \\
\text { clinic/hospital }\end{array}$ & $29(24.0) / 92(76.0)$ & $20(20.4) / 78(79.6)$ & $30(20.7) / 115$ (79.3) & 0.760 \\
\hline 3. Number of physicians, $1 / 2$ or more & $69(56.6) / 53(43.4)$ & $51(52.0) / 47(48.0)$ & $75(5 \mid .7) / 70(48.3)$ & 0.696 \\
\hline $\begin{array}{l}\text { 4. Medical standard: standard care/ } \\
\text { not standard care }\end{array}$ & $87(71.9) / 34(28.1)$ & $84(85.7) / 14(14.3)$ & |3| (9|.0)/I3 (9.0) & $0.000 *$ \\
\hline $\begin{array}{l}\text { 5. Physician's apology: } \\
\text { presence/absence }\end{array}$ & I (0.8)/II I (99.2) & I (I.0)/95 (99.0) & $10(6.8) / 136(93.2)$ & $0.008^{*}$ \\
\hline $\begin{array}{l}\text { 6. Physician's status as a specialist in the } \\
\text { type of care: yes/other (no or unknown) }\end{array}$ & $94(77.0) / 28(23.0)$ & $86(87.8) / / 2(12.4)$ & $136(93.2) / 10(6.8)$ & $0.002^{*}$ \\
\hline \multicolumn{5}{|l|}{ Medical litigation } \\
\hline $\begin{array}{l}\text { I. Introduction of evidence by } \\
\text { medical expert witness (yes/no) }\end{array}$ & $24(19.7) / 98(80.3)$ & $36(36.7) / 62(63.3)$ & $66(45.2) / 80(54.8)$ & $0.000 *$ \\
\hline $\begin{array}{l}\text { 2. Type of plaintiff: patient, patient } \\
\text { and family/family only }\end{array}$ & $86(70.5) / 36(29.5)$ & $52(53.1) / 46(46.9)$ & $67(45.9) / 79(54.1)$ & $0.000^{*}$ \\
\hline 3. Number of issues: $0-3 / 4$ or more & $56(46.3) / 65(53.7)$ & $62(63.3) / 36(36.7)$ & $87(59.6) / 59(40.4)$ & $0.023 *$ \\
\hline $\begin{array}{l}\text { 4. Ratio of damages awarded to } \\
\text { damages sought }\end{array}$ & $|2.59 \pm 22.7|$ & $23.20 \pm 29.56$ & $37.73 \pm 68.27$ & $0.000 *$ \\
\hline 5. Damages awarded (mean $\pm S D$, yen) & $3,278,991 \pm 102,107$ & $5,77 \mid, 796 \pm 819,806$ & $8,785,617 \pm 103,107$ & $0.000^{*}$ \\
\hline
\end{tabular}

\section{Discussion}

In this study, the association between physicians' explanatory behaviors and court decisions concerning breaches in the duty of physicians to explain relevant issues to patients was examined according to time period. Our three hypotheses were examined, and the data generated provided the basis for several conclusions. First, the explanatory behaviors with the greatest potential impact on the fulfillment of a physician's duty to explain were identified, ie, those directed at the patient or family that were relevant and specific to treatment, those provided prior to treatment or surgery, and those provided prior to the actual day of surgery or treatment (Table 4).

Additionally, the ratios of preferable behaviors to identified explanatory behaviors in categories including no breaches of care have increased as a function of time (Table 4), implying that courts are increasingly likely to consider inadequate physician explanations as breaches of care. The patient's right of self-determination rests on the physician's duty to explain relevant issues to the patient. Sound patient decisions must be based on explanations that are specific and relevant to treatment. Thus, it is understandable that explanations to a patient or family that were relevant and specific to treatment were related to court decisions issued between 1979 and 2008 concerning breaches of the physician's duty to explain. Indeed, between 1990 and 2008, when the patient's right of self-determination became increasingly important, the timing and day of a physician's explanation (ie, prior to surgery or treatment) were related to court decisions concerning breaches in physicians' duty to explain. Exercise of the right of self-determination requires that the patient has sufficient time to consider all options. Thus, it is also understandable that the timing and the day of a physician's explanation were related to court decisions concerning breaches in the physician's duty to explain.

Second, the data showed improvement in six of the 16 explanatory behaviors as a function of the passage of 
Table 3 Comparison of physicians' explanatory behaviors by period of decision

\begin{tabular}{|c|c|c|c|c|}
\hline & \multicolumn{3}{|c|}{ Period of court decisions } & \multirow[t]{2}{*}{$P$ value } \\
\hline & $\begin{array}{l}1979-1989 \\
(\mathrm{n}=122)^{\mathrm{a}}\end{array}$ & $\begin{array}{l}1990-1999 \\
(\mathrm{n}=98)^{\mathrm{b}}\end{array}$ & $\begin{array}{l}2000-2008 \\
(n=146)^{c}\end{array}$ & \\
\hline $\begin{array}{l}\text { I. Purpose of physician's explanation: } \\
\text { obtaining patient's consent/other }\end{array}$ & $53(51.5) / 50(48.5)$ & $60(71.4) / 24(28.6)$ & $100(76.3) / 3 \mid(23.7)$ & 0.000 \\
\hline $\begin{array}{l}\text { 2. Provision of an explanation by physician: no } \\
\text { explanation/other }\end{array}$ & $35(34.0) / 68(66.0)$ & $14(16.7) / 70(83.3)$ & $12(9.2) / 119(90.8)$ & 0.000 \\
\hline $\begin{array}{l}\text { 3. Timing of physician's explanation: prior to } \\
\text { treatment or surgery/after treatment or surgery }\end{array}$ & $50(74.6) / 17(25.4)$ & $54(77.1) / 16(22.9)$ & $99(82.5) / 21(17.5)$ & 0.406 \\
\hline $\begin{array}{l}\text { 4. Recipient of physician's explanation: patient, } \\
\text { patient and family/family only }\end{array}$ & $39(57.4) / 29(42.6)$ & $53(75.7) / 17(24.3)$ & $100(83.3) / 20(16.7)$ & $0.000 *$ \\
\hline $\begin{array}{l}\text { 5. Manner of physician's explanation to the patient: } \\
\text { oral only/oral and other methods }\end{array}$ & $36(94.7) / 2(5.3)$ & $4 \mathrm{I}(77.4) / 12(22.6)$ & $67(67.7) / 32(32.3)$ & $0.004 *$ \\
\hline $\begin{array}{l}\text { 6. Manner of physician's explanation to family: oral } \\
\text { only/oral and other methods }\end{array}$ & $33(84.6) / 6(15.4)$ & $32(80.0) / 8(20.0)$ & $64(81.0) / 15(19.0)$ & 0.851 \\
\hline $\begin{array}{l}\text { 7. Level of physician's explanation to the patient: } \\
\text { relevant and specific to treatment/not sufficiently } \\
\text { relevant or specific to treatment }\end{array}$ & II (32.4)/23 (67.6) & I5 (28.8)/37 (7I.2) & $34(35.4) / 62(64.6)$ & 0.717 \\
\hline $\begin{array}{l}\text { 8. Level of physician's explanation to family: relevant } \\
\text { and specific to treatment/not sufficiently relevant } \\
\text { or specific to treatment }\end{array}$ & $10(35.7) / 18(64.3)$ & $12(32.4) / 25(67.6)$ & $27(38.6) / 43(6 \mid .4)$ & 0.819 \\
\hline $\begin{array}{l}\text { 9. Place in which physician's explanation was } \\
\text { provided: inpatient ward/outpatient clinic }\end{array}$ & $57(55.3) / 46(44.7)$ & $48(57.1) / 36(42.9)$ & $68(5 I .9) / 63(48.1)$ & 0.734 \\
\hline $\begin{array}{l}\text { 10. Content of physician's explanation: } \\
\text { related to surgery or treatment/other }\end{array}$ & $34(27.9) / 88$ (72.I) & $40(40.8) / 58(59.2)$ & $58(39.7) / 88(60.3)$ & 0.068 \\
\hline $\begin{array}{l}\text { 11. Frequency of physician's explanation: } \\
\text { once/twice or more }\end{array}$ & $37(55.2) / 30(44.8)$ & $27(40.3) / 40(59.7)$ & $45(37.8) / 74(62.2)$ & 0.061 \\
\hline 12. Patient's consent to treatment: yes/no & $34(91.9) / 3(8.1)$ & $40(90.9) / 4(9.1)$ & $77(89.5) / 9(10.5)$ & 0.913 \\
\hline 13. Family's consent to treatment: yes/no & $23(88.5) / 3(11.5)$ & $31(88.6) / 4(11.4)$ & $59(95.2) / 3(4.8)$ & 0.404 \\
\hline 14. Written consent by patient: yes/no & $3(23.1) / 10(76.9)$ & $9(47.4) / 10(52.6)$ & $33(6 \mathrm{I} .1) / 2 \mathrm{I}(38.9)$ & $0.038 *$ \\
\hline 15. Written consent by family: yes/no & $2(18.2) / 9(81.8)$ & II $(57.9) / 8(42.1)$ & $24(61.5) / 15(38.5)$ & $0.030 *$ \\
\hline $\begin{array}{l}\text { 16. Physician's explanation prior to the day of surgery } \\
\text { or treatment: yes/no }\end{array}$ & $15(3 \mid .3) / 33(68.8)$ & $7(13.5) / 45(86.5)$ & $19(20.2) / 73(79.8)$ & 0.092 \\
\hline
\end{tabular}

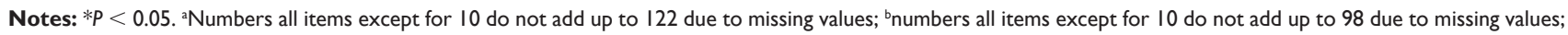
cnumbers all items except for 10 do not add up to 146 due to missing values; ${ }^{\mathrm{d}} \chi^{2}$ test or $\mathrm{G}$ test.

time and as the patient's right of self-determination has become more important. ${ }^{15,22,23}$ Specifically, the number of cases in which physicians provided explanations to obtain a patient's consent has increased, the number in which physicians' explanations were absent has decreased, the number of physician explanations to patients and family has increased, the use of verbal and other methods to provide explanations has increased, and the number of written consents provided by patients or family members has increased (Table 3).

Third, we found that improved physician explanatory behaviors during the last three decades might not necessarily fulfill a physician's legal duty to explain in medical settings (Tables 3 and 4) because explanations to the patient or the family had to contain information that was relevant and specific to the treatment and be provided prior to treatment or surgery, and be provided prior to the day of surgery or treatment to meet the criteria (Table 4). However, these three particular explanatory behaviors have not improved during the last three decades (Table 3), which carries practical implications. To fulfill the legal duty to explain, avoid the delivery of substandard care, and secure the patient's right of self-determination, explanations must be provided prior to the treatment or surgery, including prior to the day of surgery or treatment, and must be relevant and specific to the treatment in question.

This study also has several practical implications. Previously, the explanatory behaviors important for fulfilling a physician's duty to explain had not been identified. According to the elaboration likelihood model, ${ }^{26}$ people are most likely to pay careful attention to information when it is relevant to them and when it can be processed without assistance. Medical disputes and medical malpractice litigation pose immediate threats to general practitioners, and improving patient-physician communication by improving the explanatory behaviors of physicians is not a difficult task. Thus, dissemination of findings identifying the explanatory 


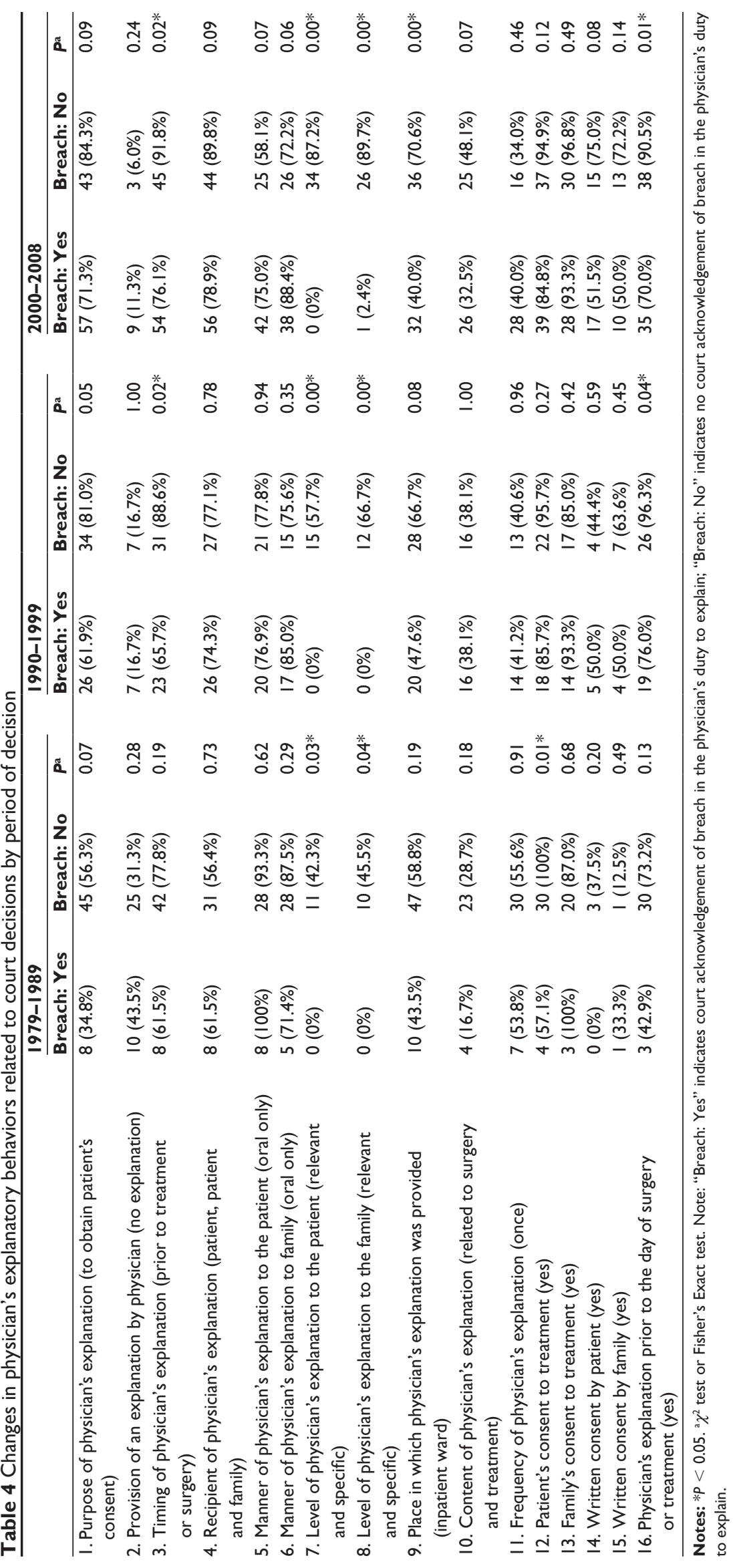


behaviors with the greatest potential impact on the fulfillment of a physician's duty to explain may lead to improved explanatory behaviors.

Finally, this study has some limitations, and the results should be interpreted with appropriate caution. First, the reliance on reported court decisions to assess communication is probably the greatest methodological weakness of this study. Additionally, no attempt was made to correlate the doctor's behaviors as reported in the court decisions with the doctor's actual behaviors as observed during patient-doctor interactions. Thus, the validity of the data on physician communication may be questioned, especially when compared with data on communication obtained via direct observation by researchers. The identities of those who received physician explanations (ie, patients, families, or both) and the manner of physicians' explanatory behaviors (eg, timing, purpose, level, recipient) were examined. These measures are related to only one aspect of communication behaviors, and data on other important communication behaviors, such as the amount of explanation or listening, could not be obtained. Further research using recordings/videotapes to delineate how actual communication behaviors affect the risk of malpractice suits is needed. Second, because decisions in only litigated cases were analyzed, the external validity of our findings requires further consideration. We analyzed adjudicated cases in which the pivotal issue was a physician's duty to explain. Two types of problems may have affected this approach. First, it is probable that the cases we analyzed were representative of all cases adjudicated during the study period in which the pivotal issue was a physician's duty to explain. Court decisions are reached by judges based on evidence, interpretation of tort laws, and the doctrine of precedent (ie, the decision in one case maintains consistency with the decisions in similar cases). However, the data analyzed included all aspects of problems related to a physician's duty to explain in a medical setting. Thus, it is highly probable that the findings are representative of all cases that were adjudicated during the study period that centered on a physician's duty to explain. The second problem concerns possible differences between medical disputes that are litigated versus those that are settled. Previous studies have shown that, in most cases, the initial incident did not contribute to the decision on whether to take legal action. Rather, secondary problems that arose in response to the original incident were the factors that precipitated decisions about whether to pursue litigation. ${ }^{27,28}$ Inappropriate responses to medical disputes included unclear or insufficiently informative explanations ${ }^{28}$ and a lack of openness or willingness to explain. ${ }^{27}$ Conversely, desirable behaviors included involving the person who was central in the original incident in the response and providing replies that were professional, courteous, polite, sympathetic, or concerned. ${ }^{28}$ These findings imply that the only difference between nonlitigated and litigated medical disputes concerns the countermeasures taken in response to the initial incidents. Thus, our findings may have some degree of external validity. Again, however, we note that our data were not based on researchers' direct observations of communications.

In summary, our data imply that the courts are increasingly likely to consider inadequate explanatory behaviors by physicians to constitute breaches in their professional duties. Additionally, physicians' explanatory behaviors, such as providing explanations relevant and specific to treatment prior to treatment or surgery, including prior to the day of surgery or treatment, are important in fulfilling a physician's duty to explain. ${ }^{2}$ Of 16 physician explanatory behaviors listed in the study, six have shown improvement during the last three decades. ${ }^{3}$ However, these improvements in physicians' explanatory behaviors was not adequate to fulfill physicians' duty to explain. Assuring adequate care by improving physician explanatory behaviors requires that physicians provide relevant and specific explanations prior to treatment or surgery, including prior to the day of surgery or treatment.

\section{Disclosure}

The authors report no conflicts of interest in this work.

\section{References}

1. Leflar RB. The regulation of medical malpractice in Japan. Clin Orthop Relat Res. 2009;467(2):443-449.

2. Ostergard N, Shanley E. Analysis and management of CRICO's highexposure claims. Forum. 1997;18(3):6-8.

3. David RA, Rhee M. The impact of language as a barrier to effective health care in an underserved urban Hispanic community. Mt Sinai J Med. 1998;65(5-6):393-397.

4. Zebiene E, Razgauskas E, Basys V, et al. Meeting patient's expectations in primary care consultations in Lithuania. Int J Qual Health Care. 2004; 16(1):83-89.

5. Takayama T, Yamazaki Y, Katsumata N. Relationship between outpatients' perceptions of physicians' communication styles and patients' anxiety levels in a Japanese oncology setting. Soc Sci Med. 2001;53(10): $1335-1350$.

6. Localio AR, Lawthers AG, Brennan TA, et al. Relation between malpractice claims and adverse events due to negligence. Results of the Harvard Medical Practice Study III. N Engl J Med. 1991;325(4):245-251.

7. Beckman HB, Markakis KM, Suchman AL, Frankel RM. The doctorpatient relationship and malpractice. Lessons from plaintiff depositions. Arch Intern Med. 1994;154(12):1365-1370.

8. Hickson GB, Clayton EW, Entman SS, et al. Obstetricians' prior malpractice experience and patients' satisfaction with care. JAMA. 1994; 272(20):1583-1587.

9. Levinson W, Roter DL, Mullooly JP, Dull VT, Frankel RM. Physicianpatient communication. The relationship with malpractice claims among primary care physicians and surgeons. JAMA. 1997;277(7): $553-559$. 
10. Brenner RJ, Bartholomew L. Communication errors in radiology: A liability cost analysis. J Am Coll Radiol. 2005;2(5):428-431.

11. De Reuver PR, Wind J, Cremers JE, Busch OR, van Gulik TM, Gouma DJ. Litigation after laparoscopic cholecystectomy: An evaluation of the Dutch arbitration system for medical malpractice. J Am Coll Surg. 2008;206(2):328-334.

12. Roter DL, Stewart M, Putnam SM, Lipkin M, Stiles W, Inui TS. Communication patterns of primary care physicians. JAMA. 1997; 277(4):350-356.

13. Sleath B, Roter D, Chewning B, Svarstad B. Asking questions about medication. Analysis of physician-patient interaction and physician perceptions. Med Care. 1999;37(11):1169-1173.

14. Applebaum PS, Litz CW, Parker LS, Berg JW. Informed Consent: Legal Theory and Clinical Practice. New York, NY: Oxford University Press; 2001.

15. The Supreme Court of Japan. Decision by the Supreme Court of Japan on November 27, 2001. Hanrei Jiho. 2002;1769:56-61. Japanese.

16. Kiuchi A, Matsumura Y, Kyakuno M, Nosaka S, Maeda S, Ehara K. Judgments on medical accidents related to accountability. The Journal of Japan Society for Clinical Anesthesia. 2006;26(7):742-749.

17. Hamasaki T, Takehara T, Hagihara A. Physicians' communication skills with patients and legal liability in decided medical malpractice litigation cases in Japan. BMC Fam Pract. 2008;9:43.

18. Hagihara A, Nishi M, Abe E, Nobutomo K. The structure of medical malpractice decision-making in Japan. J Law Med. 2003;11(2): $162-184$.
19. Hagihara A, Nishi M, Nobutomo K. Standard of care and liability in medical malpractice litigation in Japan. Health Policy. 2003;65(2): 119-127.

20. Hagihara A, Tarumi K. Association between physicians' communicative behaviors and judges' decisions in lawsuits on negligent care. Health Policy. 2007;83(2-3):213-222.

21. Yusuki J. The first affirmative decision of patient's self-determination right in the Supreme Court. Aino-Gakuin-Kiyo. 2002;15:123-128.

22. The Supreme Court of Japan. Decision by the Supreme Court of Japan on September 24, 2002. Hanrei Jiho. 2003;1803:28-33. Japanese.

23. The Supreme Court of Japan. Decision by the Supreme Court of Japan on September 8, 2005. Hanrei Jiho. 2006;1912:16-19. Japanese.

24. Tokyo District Court. Decision by the Tokyo District Court on July 28, 1995. Hanrei Jiho. 1996;1551:100-104. Japanese.

25. Kachalia A, Shojania KG, Hofer TP, Piotrowski M, Saint S. Does full disclosure of medical errors affect malpractice liability? The jury is still out. Jt Comm Journal Qual Saf. 2003;29(10):503-511.

26. Petty RE, Barden J, Wheeler SC. The elaboration likelihood model of persuasion. In: DiClemente RJ, Crosby RA, Kegler MC, editors. Emerging Theories in Health Promotion Practice and Research. San Francisco, CA: Jossey-Bass; 2002.

27. Vincent C, Young M, Phillips A. Why do people sue doctors? A study of patients and relatives taking legal action. Lancet. 1994;343: 1609-1613.

28. Bark P, Vincent C, Jones A, Savory J. Clinical complaints: A means of improving quality of care. Qual Health Care. 1994;3:123-132.
International Journal of General Medicine

\section{Publish your work in this journal}

The International Journal of General Medicine is an international, peer-reviewed open-access journal that focuses on general and internal medicine, pathogenesis, epidemiology, diagnosis, monitoring and treatment protocols. The journal is characterized by the rapid reporting of reviews, original research and clinical studies across all disease areas.

\section{Dovepress}

A key focus is the elucidation of disease processes and management protocols resulting in improved outcomes for the patient. The manuscript management system is completely online and includes a very quick and fair peer-review system. Visit http://www.dovepress.com/ testimonials.php to read real quotes from published authors. 